\title{
A REVIEW ON NOVEL APPROACHES FOR ORAL DELIVERY OF INSULIN
}

\author{
*Pandit Neha, Joshi Tanuj \\ Department of Pharmaceutical Sciences, Kumaun University, Bhimtal, Uttarakhand, India \\ *Corresponding Author's Email: panditneha21@gmail.com
}

Received 20 May 2015; Review Completed 23 June 2015; Accepted 08 July 2015, Available online 15 July 2015

\begin{abstract}
Objectives: A review article on novel approaches on oral insulin delivery.

Data Sources: Review articles on oral insulin delivery, Books.

Study selection: This review consist of importance as well as current approaches for oral insulin delivery like liposomes, nanospheres, nanocubeics, erythrocytes, thiolated chitosan tablets, chitosan microspheres etc.

Summary of content article: Type 1 diabetes mellitus is a metabolic disorder which arouse as a major health problem worldwide. Clinical management of insulin is done by insulin replacement therapy and current route of its administration is through subcutaneous injection having many challenges. To overcome the problems associated with insulin injections novel approaches for insulin administration are being explored. If insulin is administered orally, in the stomach rapid enzymatic degradation of insulin occurs and in the intestine insulin is digested and hence inactivated by the action of proteolytic enzymes occurs. This review consist of importance as well as current approaches for oral insulin delivery like liposomes, nanospheres , nanocubeics, erythrocytes, thiolated chitosan tablets, chitosan microspheresetc. This review also gives the information about current market status of oral insulin ${ }^{5}$.

Conclusion: The oral route is considered to be most acceptable and convenient route of administration for chronic therapy. Attempts have been made to achieve oral insulin delivery using various systems. Liposomes, microemulsions, nanocubicles, thiolated chitosan, chitosan microspheres and so forth have been prepared for the oral delivery of insulin.

Keywords: oral insulin, approaches for oral insulin delivery , current market status.
\end{abstract}

\section{INTRODUCTION}

Diabetes mellitus (DM), is a heterogeneous group of metabolic disorders in which there is elevation in blood glucose level over a prolonged time period. ${ }^{1}$ Diabetes is found in about 300 million people world-wide, and the number keep on increasing. It occurs as the body is unable to produce enough insulin as much required, either because of impaired insulin secretion, impaired insulin action, or both. ${ }^{1}$ Lack of proper treatment of diabetes may lead to manycomplications. ${ }^{2}$ Acute complications because of untreated diabetes include diabetic ketoacidosis and nonketotic hyperosmolar coma ${ }^{3}$. Serious chronic complications of untreated diabetes include cardiovascular disease, stroke, chronic kidney failure, foot ulcers, retina damage.

Diabetes occurs due to either the pancreas not producing enough insulin as much required by the body or the cells of the body not responding properly to the insulin produced i.e. cells desensitized of insulin produced. There are three main types of diabetes mellitus:

- Type 1 DM occurs due to the failure of beta cells of the islets of Langerhans in the pancreas to produce enough insulin as per requirement, leading to 두 2011-15, JDDT. All Rights Reserved insulin deficiency. It is also known as "insulindependent diabetes mellitus" (IDDM). The cause of Type $1 \mathrm{DM}$ is exactly not known. ${ }^{2}$ It can be further differentiated as immune-mediated or idiopathic. Majority of cases of type 1 diabetes is of the immune-mediated nature, that occurs due to T-cellmediated autoimmune attack leads to the loss of beta cells and thereforeinsulin. ${ }^{3}$

- Type 2 DM initiates with insulin resistance or insulin desensitization, a condition in which cells fail to respond to insulin properly. ${ }^{2}$ Chronic persisting of such condition causes a lack of insulin may also develop. ${ }^{4}$ It is also known as "non insulindependent diabetes mellitus" (NIDDM) or "adultonset diabetes". The major cause is excessive body weight and lack of exercise. ${ }^{2}$ Generally oral hypoglycemic drugs are administered for such cases for example: sulphonylurea's, biguanides etc.

- Gestational diabetes, is the third main form of DM and occurs during pregnancy, when pregnant women without a previous history of diabetes develop a high blood glucose level. It occurs in about $2-10 \%$ of all pregnancies and may improve or disappear after delivery. ${ }^{6}$

ISSN: 2250-1177

CODEN (USA): JDDTAO 
The current route of insulin administration is via subcutaneous route through which insulin is delivered to the body in non-physiological manner having many challenges. Hence novel approaches for insulin delivery are being explored and investigated. Challenges which precipitate via oral route of administration of insulin are: rapid enzymatic degradation in the stomach, inactivation and digesion by proteolytic enzymes in intestinal lumen and poor permeability across intestinal epithelium because of high molecular weight and lack of lipophilicity. Nanosphere, thiolated chitosan tablets, chitisan-microsphers, microemulsions, liposomes, nanocubicles and so forth have been prepared for the oral delivery of insulin. 5

\section{PROBLEMS ASSOCIATED WITH PRESENT ROUTES FOR INSULIN ADMINISRATION}

The present route of insulin administration is by subcutaneous route by which insulin is presented to the body of patient in a non - physiological manner. ${ }^{5}$ This route of administration of insulin has many challenges.

For a diabetes mellitus patient insulin replacement therapy is performed injecting insulin subcutaneously frequenty, is having many inherent disadvantages which include local pain, inconvenience due to repetative injection, and hypoglycemia may occurs as a result of over dose, itching, allergy, hyperinsulanemia, and insulin lipodistrophy around the site of injection. Further, clinical trials have shown that even on injectables insulin treatment, a significant percentage of patients fails to attain lasting glycemic control due to non-complience. ${ }^{5,15}$ As of these problems , novel approaches for insulin delivery are being explored , including oral and transdermal ,nasal, rectal, pulmonary, uterine and ocular delivery as well as s.c. implants . Delivery options that use dermal, nasal, and oral have been explored. ${ }^{5,16,17}$

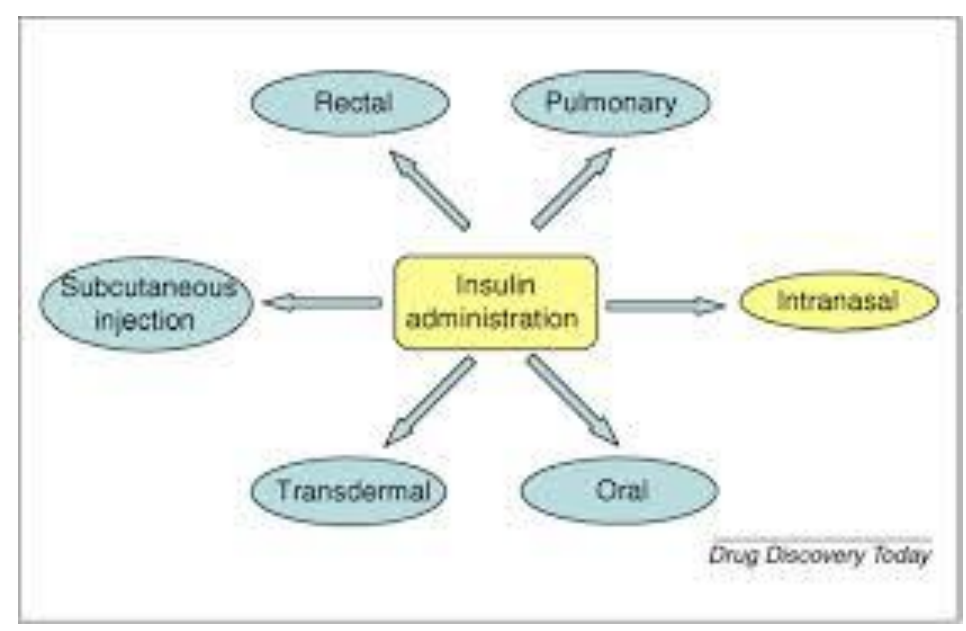

Figure 1: Possible routes insulin administration ${ }^{9}$

\section{IMPORTANCE OF ORAL DELIVERY OF INSULIN}

The oral route of drug delivery is considered to be most convenient route with good patient compliance for administration in case of chronic therapy. Administration of insulin orally will help to eliminate the pain caused by injection, psychological barriers associated with multiple daily injections such as needle anxiety ${ }^{7}$ and possible infections. ${ }^{8}$ Further, oral insulin is advantageous because it is delivered directly on the liver, its primary site of action, via the portal circulation, a mechanism very similar to endogenous insulin, subcutaneous insulin treatment subcutaneous insulin treatment however does not replicate the normal dynamics of endogenous insulin release, resulting in failure to achieve release a lasting glycemic control in patients. ${ }^{5,11,12,13}$ 


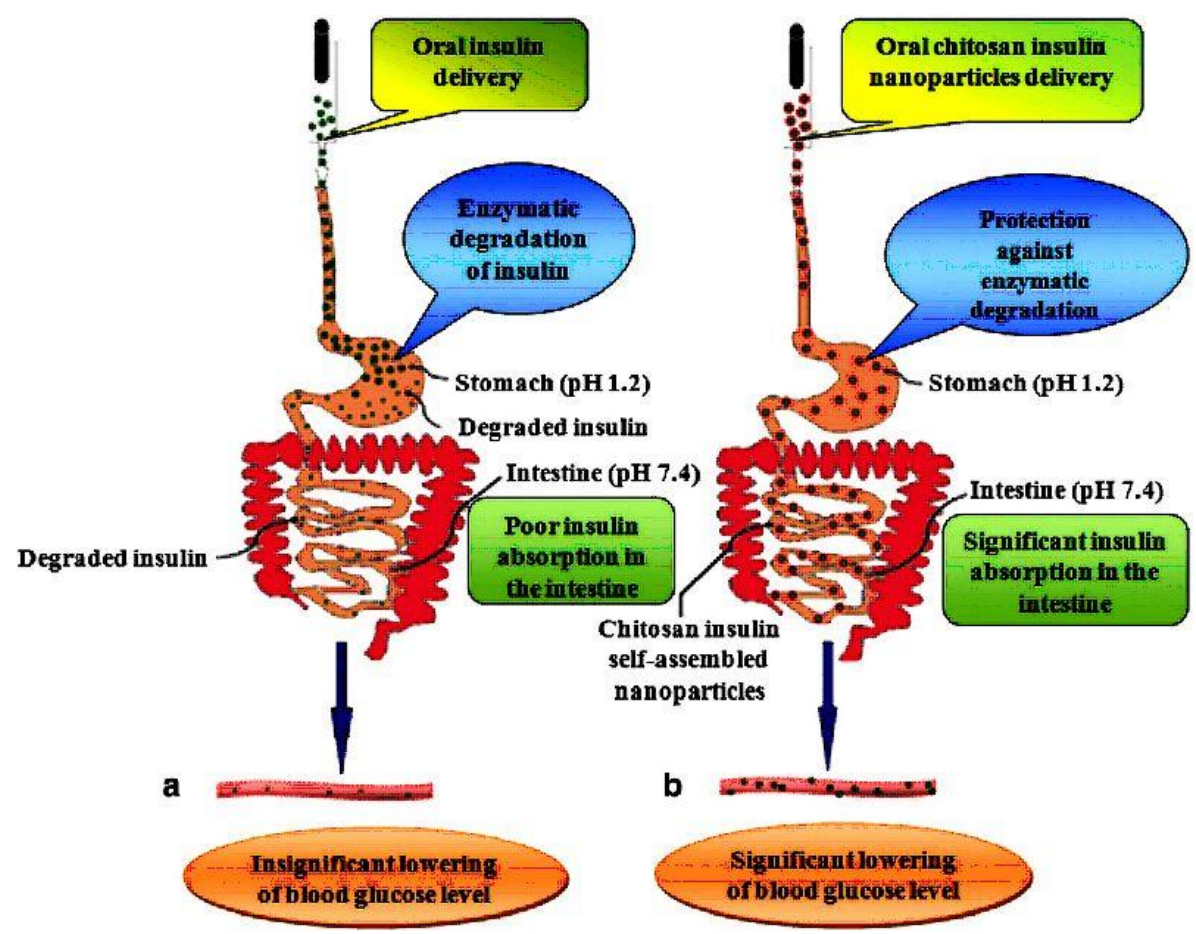

Figure 2: Development of effective oral insulin delivery ${ }^{9}$

\section{CHALLENGES TO OVERCOME FOR ORAL INSULIN DELIVERY}

Because of inactivation and digestion by proteolytic enzymes in the intestinal lumen, rapid enzymatic degradation in the stomach, and poor permeability across intestinal epithelium because of its high molecular weight and lack of lipophilicity, peptides and proteins such as insulin cannot be administered via the oral route. ${ }^{18,19,20}$ The oral bioavailability of most of the peptides and proteins therefore is less than $1 \% .^{5}$ The challenge here is to improve the oral bioavailability to at least between $30-50 \%{ }^{21}$

\section{- ENZYMATIC \\ BARRIERS \\ GASTROINTESTINAL TRACT}

IN

The digestive process occurring in the gastrointetinal tract leads to breakdown of all type of proteins and peptides. ${ }^{22}$ Insulin therefore undergoes enzymatic degradation by pepsin and pancreatic proteolytic enzyme such as trypsin and alpha-chymotrypsin. ${ }^{5,14,23}$ Insulin degraded by cytosolic enzyme insulin degrading enzyme (IDE). ${ }^{24}$ Overall, insulin is subjected to acid catalysed degradation in the stomach, luminal degradation in the intestinal and intracellular degradation. ${ }^{5}$ Brush border enzymes however does not cause proteolytic breakdown of insulin. ${ }^{14}$ Hence enzymetic barriers has to be overcome for insulin oral delivery.

\section{- INSULIN LOW PERMEABILITY TO INTESTINAL MUCOSA}

Insulin has low permeability through the intestinal mucosa because insulin is hydrophilic macromolecule hence cannot diffuse across epithelial cells through lipid-bilayer cell membranes of intestinal mucosa to the blood stream. ${ }^{8,25}$ There is no evidence of active transport for insulin. ${ }^{5,26}$ It has been found however that insulin delivery to the mid-jejunum protects insulin from gastric and pancreatic enzymes and release from the dosage form is enhanced by intestinal micro flora. ${ }^{5,26,27}$ Hence targeting insulin dosage form to mid jejunum may be effective with increased bioavailability.

\section{- STRENGTH OF DOSAGE FORM:}

The three-dimensional molecular structure plays important role in the activity of proteins. Proteins might tend to physical and chemical degradation at the time of forming dosage form. Proteins' physical degradation involves modification of the native structure to a higher order structure while chemical degradation involving bond cleavage that results in the formation of a new stuctures. ${ }^{5,14}$ At the time of dosage formulation processing proteins must be characterized for change in conformation, size, shape, surface properties, and bioactivity. ${ }^{5}$ Usinglight scattering, spectrophotometric techniques, gel filtration, x-ray diffraction, differential scanning calorimeter, and electrophoresis changes in conformation, size, shape of protein can be observed.

\section{APPROACHES FOR ORAL ADMINISTRATION OF INSULIN ${ }^{5}$}

\section{Already Attempted Oral Delivery Systemsof Insulin: ${ }^{5}$}

Generally bioavailability of most of the peptides is very negligible or not possible after oral administration in gastrointestinal tract ${ }^{28}$ Hence developing successful oral insulin delivery system need to overcome the enzymatic and physical barriers ${ }^{22}$ and effectively conversing the bioactivity during formulation processing. ${ }^{14}$ In developing oral protein delivery systems with high bioavailability, three practical approaches might be most helpful: $:^{5,11}$

1. Effectively modifying physiochemical properties such as lipophilicity and enzyme susceptibility. 
2. Addition of novel function to macromolecules (proteins and peptides).

3. Using improved carrier systems.

Following approaches can be categorized as various oral delivery systems which have been attempted for oral delivery of insulin either singly or in a synergistic manner:

\section{Insulin penetration enhancers through intestinal mucosa $^{5}$ :}

Insulinis a hydrophilic molecule adsorbed to the apical membrane and is internalized by endocytosis. ${ }^{5,14}$ Tight junctions present between each of the cells in the epithelium prevent transport across the cell of water and aqueous soluble compounds. Hence, approaches are made for modulating tight-junction permeability to increase paracellular transport have been studies. ${ }^{5}$ A number of absortion enhancers are available that cause these tight junctions to open transiently allowing watersoluble proteins to pass. Use of safe excipients in the formulation may enhance absorption ${ }^{5,29}$ Excipients like bile salts, surfactants, trisodium citrates, chelating agents like EDTA ${ }^{30}$, labrasol ${ }^{31}$ may be considered to be safe but drawbacks with it are lack of specificity for insulin, i.e., they allow other undesired content of the intestinal tracts including toxins and pathogens through it to the systematic bloodstream ${ }^{32}$, and risk of damage to mucous membranes by surfactants and damage of cell membrane by chelators ${ }^{33}$. some further work on penetration enhancers have proven mucoadhesive polymers to be safe and efficient intestinal permeation enhancers for the absorption of proteineceous drugs. 54 ,

\section{Enzyme Inhibitors: ${ }^{5}$}

Enzyme inhibitors can be used to avoid the rapid enzymatic degradation of insulin by enzyme pepsin in stomach and other pancreatic proteolytic enzymes in gastro intestinal tract. Enzymes inhibitors slowdown the rate of degradation of insulin in gastrointestinal tract which in return increases the amount of insulin available for absorption. ${ }^{14}$ The use of enzyme inhibitors in long term therapy however is considered to be highly risk because of possible absorption of unwanted proteins, disturbance of digestion of nutritive proteins $\&$ stimulation of protease secration. ${ }^{41}$ The earliest studies regarding enzyme inhibitors were carried out with sodium cholate along with aprotinin which improved insulin absorption in rats. ${ }^{5,36}$ Significant hypoglycemic effects were also obtained following large intestinal administration of insulin with camostat mesilate, bacitracin. $^{5,37}$ Other inhibitors which have shown promise effects are leupeptin ${ }^{38}$, FK- $448^{39}$, a potent \& specific inhibitor of chymotrypsin \& chicken \& duck ovomucoid. ${ }^{14}$ In one study, polymers cross linked with azoaromatic groups formed an impervious film to protect insulin from digestion in the stomach \& small intestine. ${ }^{5,40}$

\section{Modification of chemical structure: ${ }^{5}$}

Effective modification in the chemical structure of proteins and peptides may result in the appreciable enhancement in bioavailability by increasing its stability against possible enzymaytic degradation or its membrane penetration. Since proteins are structurally have more complex chemical structure as compared to peptides hence this approach is more applicable to peptides as compared to proteins. For example, substitution of D-amino acids for L-amino acids in the primary structure can improve the enzymatic stability of peptides $^{5}$. A diacyl derivative of insulin maintains its biological activity and also increases its absorption from the intestine. ${ }^{5}$

\section{VARIOUS CARRIER SYSTEMS:}

\section{Liposomes: ${ }^{5}$}

Dose-dependent hypoglycemia is observed in case of insulin-entrapped liposomes. ${ }^{5}$ Liposomes with varying composition have been prepeared by researchers via two methods: solvent evaporation hydration and solvent spherule evaporation. ${ }^{5,42}$ Liposomes which contain lecithin 100mg, cholesterol $20 \mathrm{mg}$, insulin 150 units, and Tween $1 \% \mathrm{v} / \mathrm{v}$ were found to be most effective for this purpose. ${ }^{5}$ The effect of insulin-liposome was prolonged in diabetes-induced rabbits than that of normal rabbits. ${ }^{5}$ The pharmacodynamics results of the insulin-liposome system was comparable with the action of $1 \mathrm{U} / \mathrm{kg}$ of insulin administered subcutaneously. ${ }^{5}$

\section{Hydrogels: ${ }^{5}$}

These are cross-linked networks of hydrophilic polymers, which are able to absorb large amounts of water and swell, while maintaining their threedimensional structure. ${ }^{5,43}$ Complexation hydrogels are suitable candidates for oral delivery of proteins and peptides due to their abilities to respond to changes in $\mathrm{pH}$ in the GI tract and provide protection to the drugs from the harsh environment of the GI tract. ${ }^{5,18}$

\section{Nanospheres: 5}

Iinsulin-loaded nanospheres was prepared by polymerization of isobutyl cyanoacrylates (IBCA) in an acidic medium by Damge et al. ${ }^{5,44}$ These nanosphere showed a mean size of $145 \mathrm{~nm}$ and an association rate of $1 \mathrm{U}$ of insulin per milligram of polymer. ${ }^{5}$ These nanospheres were displayed in an oily medium (Miglyol 812) containing surfactants (Polox-amer 188 and deoxycholic acid)band evaluated for in vitro and in vivo degradation. ${ }^{5}$ No in vitro degradation was observed due to proteolytic enzyme. ${ }^{5}$ When these nanosphere (100 U per kilogram of body weight) were administered perorlly in streptozotocin induced diabetic rats , a 50\% decreases in fasted glucose levels from the second hours up to 10-13 days was observed ${ }^{5}$. This effect last for very less time period (2days) or absent when nanospheres were dispersed in water $^{5}$. Using $\mathrm{C}^{14}$-labelled nanospheres loaded with $\left(\mathrm{I}^{125}\right)$ insulin or its metabolites in the gastrointestinal tract, blood, and liver while the excretion was delayed when compared to $\left(\mathrm{I}^{125}\right)$ insulin nanoassociated to nanospheres. ${ }^{5}$ 

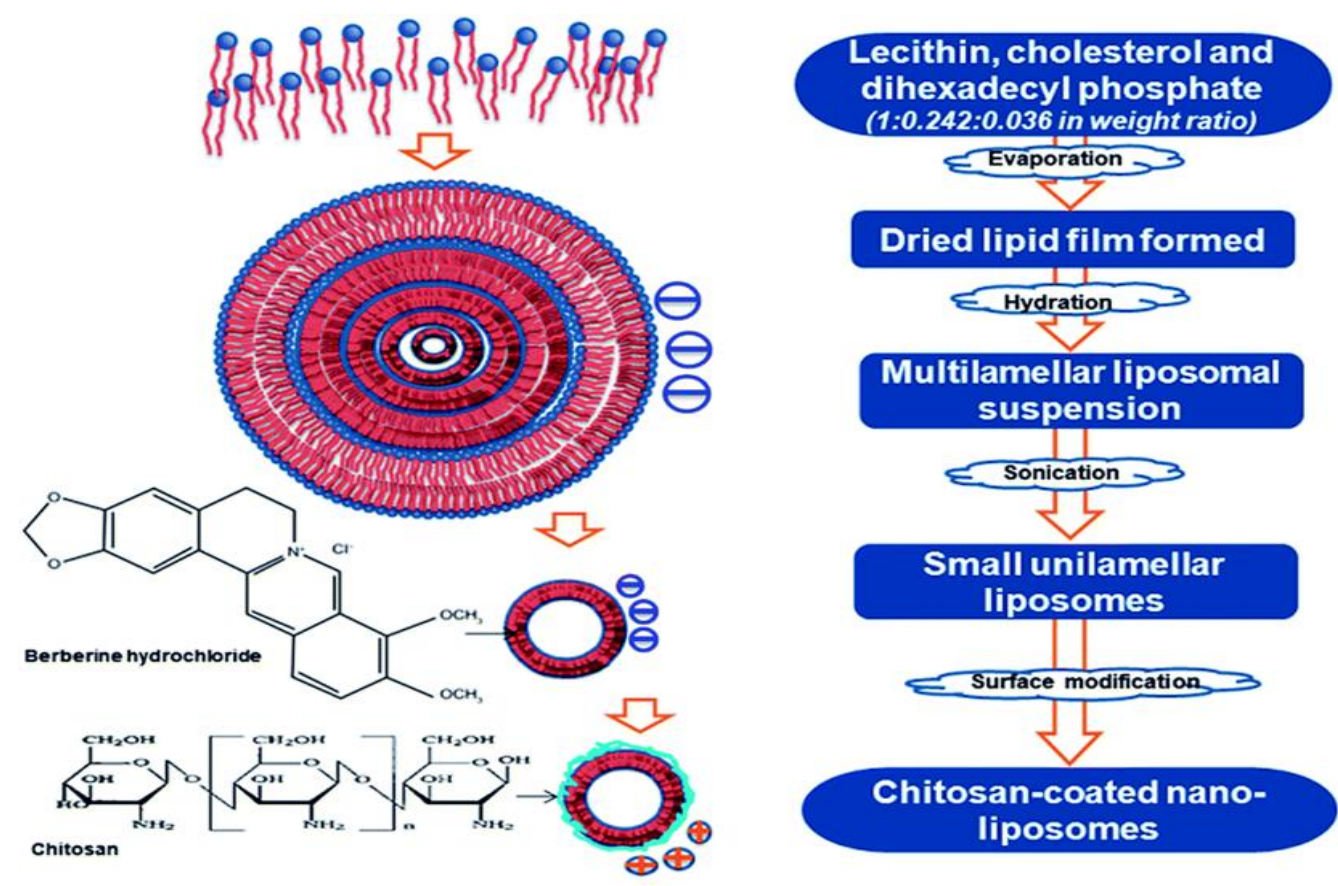

Figure 3: Formulation of chitosan coated nanoliposomes ${ }^{9}$

(a)

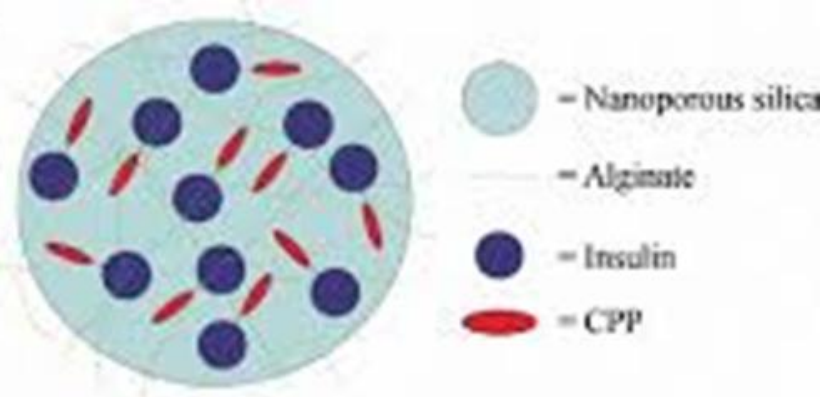

(b)

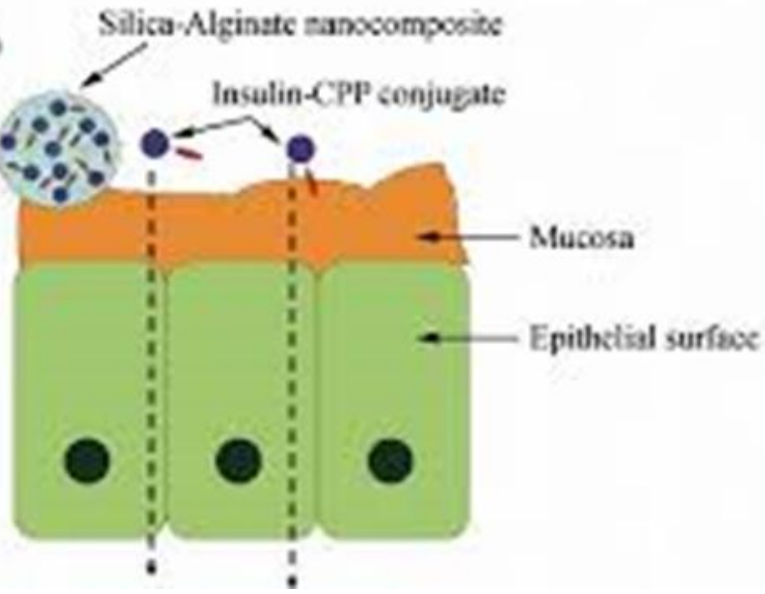

Figure 4: Silica alginate nanocomposite for insulin delivery ${ }^{9}$ 


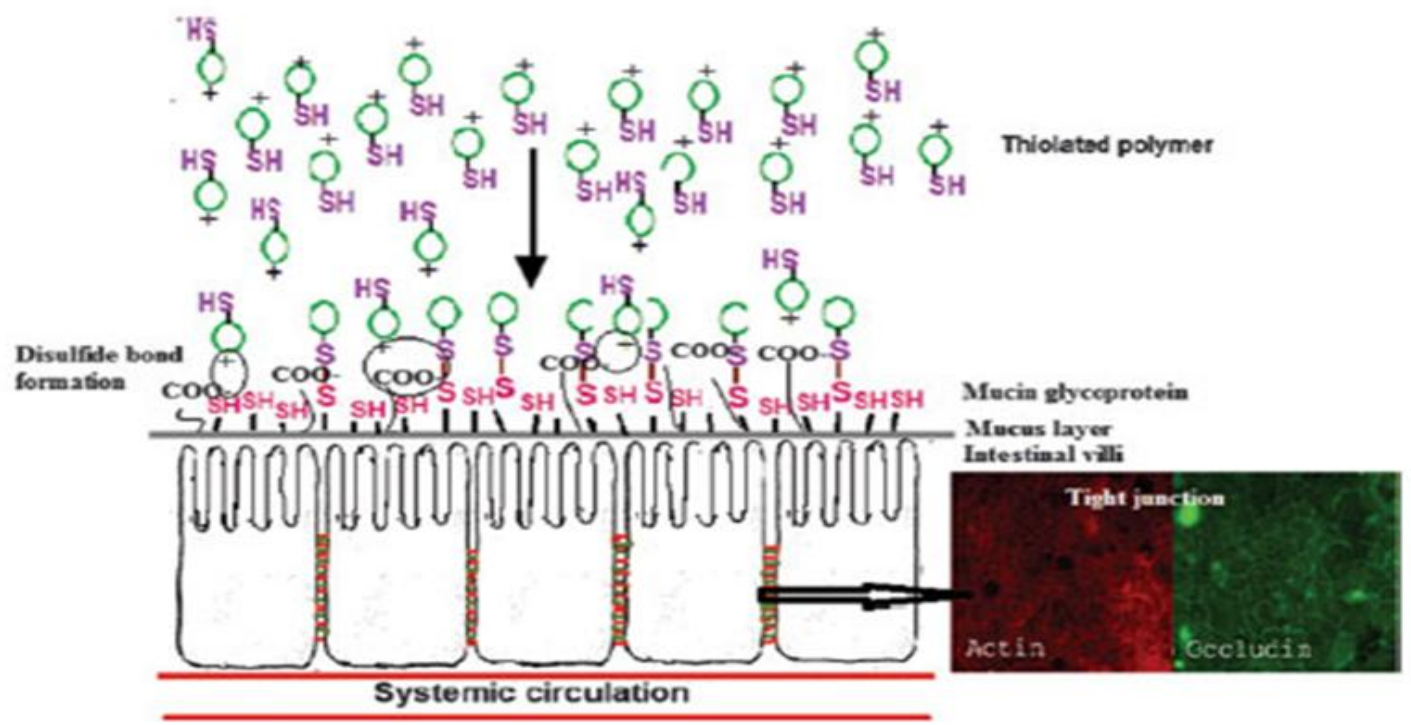

Figure 5: Thiolated polymer for oral insulin delivery ${ }^{9}$

\section{Erythrocytes: ${ }^{5}$}

Human red blood cells have been developed as oral carrier systems for human insulin ${ }^{5}$. In a study by AlAchi et al., male Wistar rats were made diabetic by a single intraperitoneal injection of streptozocin $(100 \mathrm{mg} / \mathrm{kg}))^{5,45}$ Rats received orally one of the following (100 U, 2ML): an insulin solution, a ghostsinsulin suspension, a vesicles-insulin suspension, a liposomes-ghosts-insulin suspension, or a liposomesvesicles-insulin suspension. ${ }^{5}$ Free-carrier suspensions or sodium chloride solution $(0.9 \%)$ were given orally as controls. ${ }^{5}$

Blood glucose concentration was noted before administration and at $1,2.3,4,5,6$, and $7 \mathrm{~h}$ post administration $^{5}$. Results showed that all treatment groups, except liposomes-ghosts-insulin, were significantly different statistically from their respective controls (i.e., the free carriers). ${ }^{5}$

\section{Nanocubices: ${ }^{5}$}

Chung et al developed a liquid formulae that can be easily dispersed in water to produce particles named "Nanocubicles". 46 These nanocubicles containing insulin were administered to fasted streptozotocin induced diabetic rats. ${ }^{5}$ For comparison, an aqueous solution of insulin in water was also administered. Nanocubicles without insulin and insulin in phosphate buffer saline (PBS) were administered as controls. Blood glucose concentration and insulin concentration were measured 1,2,3,4, and 6 hours after administration of insulin formulation. ${ }^{5}$ In vitro experimention showed that the particles were absorbed by Caco- 2 cells at a high ratio. ${ }^{5}$ It was observed in these studies that the serum glucose concentration was controlled for more than 6 hours after oral insulin administration but returned to the basal concentration in 3 hours when 1 $\mathrm{IU} / \mathrm{kg}$ of insulin was injected through intravenous route. ${ }^{5}$

Microspheres: ${ }^{10}$ Insulin-loaded microspheres are composed of chitosan 3\% (w/v), and loading $120 \mathrm{IU}$ insulin were produced by emulsion cross-linking method. ${ }^{10}$ Cross-linking time for it is almost $5 \mathrm{~h}$ and glutaraldehyde $3.5 \%$ (v/v) is used as cross-linker. ${ }^{10}$ To predict release of insulin from chitosan microspheres swelling ratio studies were evaluated. Bacitracin and sodium taurocholate are incorporated in the formulations as proteolytic enzyme inhibitor and absorption enhancer, respectively. ${ }^{10}$ In vitro insulin release studies are performed in phosphate buffer $\mathrm{pH}$ 7.4 and also in $\mathrm{HCl} \mathrm{pH} 2$ with and without trypsin. ${ }^{10}$ In vitro release showed a controlled profile up to $12 \mathrm{~h}$ and the formulation containing $0.15 \%(\mathrm{w} / \mathrm{v})$ of bacitracin revealed a maximum biological activity of about 49.1 $4.1 \%{ }^{7}$. Mathematical modeling using Higuchi and Korsmeyer-Peppas suggested a non-Fickian diffusion as the mechanism of insulin release. Insulin-loaded chitosan microspheres for oral delivery showed to be an innovative and reliable delivery system to overcome conventional insulin therapy. ${ }^{10}$

Microspheres of chitosan are extensively used for providing a controlled release of peptides and proteins, such as insulin. ${ }^{47}$ It helps in enhancing the bioavailability of peptide, as well asthe uptake of other hydrophilic substances through epithelial layers with improved protection against the unfavorable and degragating environment ofstomach upon oral administration. $^{47,48}$ Chitosan is a polymer with mucoadhesive properties that increases the contact with mucosa, where drugs are absorbed, resulting in a concentration gradient required for its absorption. ${ }^{49,50}$ In vitro profiles of drugs are important or the development of new drug delivery systems as an assessment of bioequivalence. ${ }^{10}$ The drug release profile is linked to the system's properties and determines the amount of drug available for absorption. ${ }^{51}$ Aspects related to drug absorption, biodistribution, metabolism and elimination (the so-called ADME processes) are therefore of upmost relevance to predict the efficiency of delivery systems by in vitro studies. The type of drug and matrix, its polymorphic form, crystallinity, particle size, and solubility can influence the release profile. ${ }^{52}$ Models of drug release are often applied to predict controlled release in delivery systems such as chitosan 
microspheres; however, it does not provide any information on the mechanisms that control the process. The use of empirical models for simulating drug release profiles is a function of time related to the amount of drug released from the pharmaceutical dosage form. ${ }^{53}$ The quantitative values are interpreted bygeneric equations that mathematically translate the release curve. To understand dissolution profiles, mathematical models and statistical analysis are used for formulation and evaluation. ${ }^{54}$ To describe the insulin releasing mechanism from chitosan microspheres, release profiles were analyzed applying 4 different mathematical models, i.e. zero order, first order, Higuchi and Korsmeyer-Peppas. In the zero order kinetics, drug dissolution profiles is slow as pharmaceutical systems do not disaggregate, assuming no changes in dissolution area which is maintained under equilibrium. The equation translating this kinetic model is: ${ }^{10}$

$\mathrm{Q}_{1}=\mathrm{Q}_{0}+\mathrm{K}_{0} \mathrm{t}$

where $\mathrm{Q}_{1}$ is the amount of drug dissolved in time $t, \mathrm{Q}_{0}$ is the initial amount of drug in the solution (generally, $\mathrm{Q}_{0}=0$ ) and $\mathrm{K}_{0}$ is the zeroorder release constant. The graphic of drug dissolved versus timewill be linear. ${ }^{10}$

In first order kinetics, the dissolution phenomenon of a solid particle in a liquid media implies a surface action and from severaldeductions. The equation in decimal logarithms can be depicted as: ${ }^{10}$

$\log \mathrm{Q}_{\mathrm{t}}=\log \mathrm{Q}_{0}+\mathrm{K}_{1} \mathrm{t} / 2.303$

where $\mathrm{Q}_{\mathrm{t}}$ is the amount of drug released at time $\mathrm{t}, \mathrm{Q}_{0}$ is the amount of drug in the solution, and $K_{1}$ is the first order release constant. The graphic of the decimal logarithm of the released amount of drug versus time will be linear. This model is usually applied for dissolution profiles of water-soluble drugs in porous matrices. $^{10}$

Higuchi model is based on the quantification of drug release derived by applying in this equation. This model describes a direct proportionality between the cumulative amount of drug released overtime based on a pseudo-steady-state approach. ${ }^{55,56}$ For Higuchi model, the drug release can be defined as the mass transfer of drug molecules from the dosage form to the surrounding medium in which drug release takes place. Higuchi equation allows device optimization, underlying drug release mechanisms. ${ }^{56}$ Higuchi model describes the release of drugs as the square root of time based on the Fickian diffusion and hence forth the simplified equation is: ${ }^{10}$

$\mathrm{f}_{\mathrm{t}}=\mathrm{K}_{\mathrm{H}} * \mathrm{t}^{1 / 2}$

where $\mathrm{K}_{\mathrm{H}}$ is the constant reflecting the design variables of thesystem. 57

Korsmeyer-Peppas model is based on the Fick's Law. This modelis used to describe the release of the solute when the prevailing mechanism is a combination of drug diffusion -Fickian transport-, and in Case II transport -non-Fickian-, controlled by the relaxation of polymer chains. ${ }^{57,58}$ Korsmeyer-Peppas model is useful to predict the release mechanism in the first $10 \mathrm{~h}$ being described bythe following equation: ${ }^{10}$

$\mathrm{M}_{\mathrm{t}} / \mathrm{M}_{\infty}=\mathrm{K} * \mathrm{t}^{\mathrm{n}}$

Where $M_{t} / M_{\infty}$ is the fraction of drug released at time $t$, $\mathrm{K}$ is the rate constant, and $\mathrm{n}$ is the diffusion exponent. According to this model, the value of $\mathrm{n}$ identifies the release mechanism of drug. Values of $n$ between 0.5 and 1.0 indicate anomalous transport kinetics, $n$ approximately 0.5 indicates the pure diffusion controlled mechanism (Fickian diffusion). The smaller $\mathrm{n}$ values below 0.5 may be dueto drug diffusion partially through a swollen matrix and water filled pores in the formulations. ${ }^{59,60}$ This model is often applied for the analysis of the release profile of drugs in polymeric systems. ${ }^{10}$

\section{FURTHER APPROACHES: ${ }^{5}$}

Tablets: ${ }^{5}$

Thiolated chitosan insulin tablets: ${ }^{5}$ The another approach for improving efficacy of orally administered insulin is by using thiolated chitosan. 2-Iminothiolane was covalently linked to chitosan and the resulting chitosan-TBA (chitosan-4-thiobutylamidine) conjugate exhibited $453.5=64.1$ micromole thiol group per gram of polymer $^{61}$. Bowman-Birk-Inhibitor (BBI) and Elastatinal two enzyme inhibitors, were covalently linked to chitosan. Chitosan-TBA conjugate $(5 \mathrm{mg})$, insulin $(2.75 \mathrm{mg})$, the permeation mediator reducer glutathione $(0.75 \mathrm{mg})$, and the two inhibitor conjugates (in each case $0.75 \mathrm{mg}$ ) were compressed to make chitosan-TBA-insulin tablets. Control tablets were also prepared using chitosan and insulin. Chitosan-TBAinsulin tablets produced a controlled release of insulin over $8 \mathrm{~h}$. In vitro mucoadhesion studies suggests that the mucoadhesive / cohesive properties of chitosan were at least 60 -fold improved by the immobilization of thiol groups on the polymer.

\section{Microemulsions: ${ }^{5}$}

Cho and Flynn developed water-in-oil microemulsions in which the aqueous phase is insulin and oil phase is lecithin, non-esterifies fatty acids and cholesterol in critical proportions ${ }^{28}$. In vivo studies demonstrated that microemulsions substantial reduction in blood glucose level. Recent research has focused on enteric-coated dry emulsion formulations prepared from solid-in-oil-inwater emulsions. These mode of administration responded to changes in external environment suggesting potential application for oral insulin delivery. ${ }^{25}$

\section{Oral Insulin pills: ${ }^{5}$}

This mode of insulin administration has so many limitations associated with it and efficacy regarding it has been hard to demonstrate. Main focus of research regarding this mode of administration is to overcome these limitations by stabilizing the degradation, improving the permeability, and adding absorption promoters to protect the insulin as it passes through the stomach. 


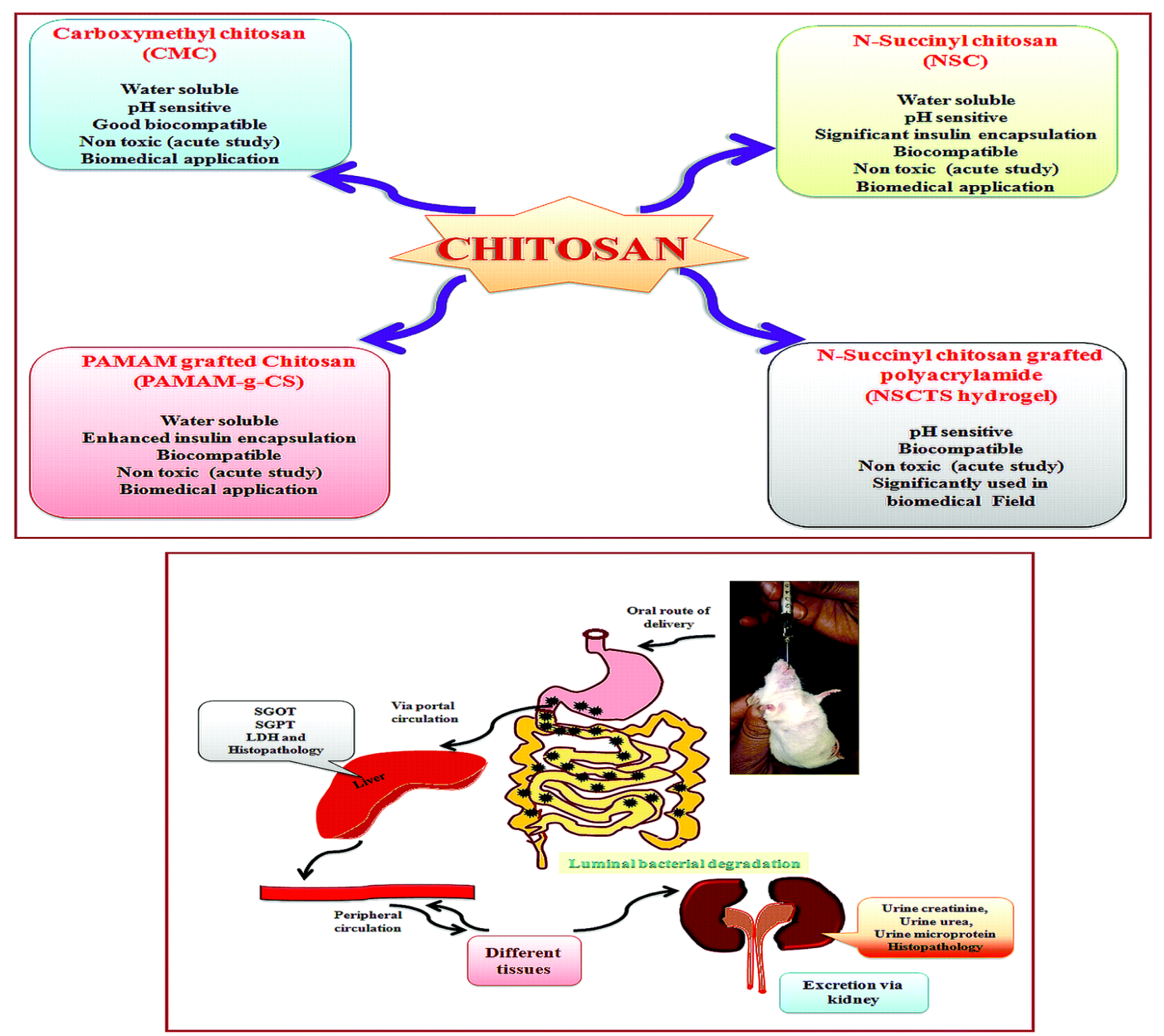

Figure 6: Chitosan as an effective polymer for oral administration of insulin ${ }^{9}$

\section{Oral Spray: ${ }^{5}$}

Oral mouth spray containing insulin when administered would be absorbed through the lining of the mouth and throat. The liquid formulation allows the insulin to be absorbed by the mucus membranes in the cheeks, tongue, and throat. The benefit from oral spray is identical to an insulin injection in its ability to lower blood glucose levels.

\section{Pulmonary or inhaled insulin: ${ }^{5}$}

In case of inhalational delivery system of insulin, a dose of insulin, either in liquid or dry powder form, delivered through the mouth, directly into the lungs, where it enters the blood circulation as rapid-acting insulin. The highly permeable alveolar epithelium and large surface area of the lungs provide an effective, efficient portal for macromolecular delivery i.e. inhaled insulin.

\section{MARKET STATUS OF ORAL INSULIN PRODUCTS: ${ }^{5}$}

\section{IN-105 (Biocon, Bangalore) ${ }^{5}$}

Biocon is developing the IN-105 conjugated insulin molecule, administered as a tablet. ${ }^{5}$ This oral insulin pill has polymers added at specific locations in the B chain of the insulin to prevent insulin from getting degraded in the stomach by degragating environment (insulin is made up of two polypeptide chains namely, chain- with 21 amino acids and chain-B with 30 amino acids, which are held together by two disulfide bonds). ${ }^{5}$ Biocon's R\&D group has successfully developed a carefully selected formulation to give consistent absorption through the intestines, delivering the glucose-lowering effect. ${ }^{5}$ In the clinic, this molecule has completed phase 1 trials and is expected to enter phase 2 in India later this year to illustrate proof of concept. ${ }^{5}$ The encouraging results of the phase $1 \mathrm{a}$ and $1 \mathrm{~b}$ studies represent a pivotal hurdle crossed in the development on IN-105 as a product. ${ }^{5}$

\section{Oral-Lyn (Generex Biotechnology, Canada) ${ }^{5}$}

Oral-Lyn is the proprietary oral insulin spray product of company Genex Biotechnology, Canada. Oral-Lyn contains a liquid formulation which is absorbed into the body by the lining of the inner mouth using the company's proprietary RapidMist device. ${ }^{5}$ As it is buccally absorbed, no insulin is deposited in the lungs by the Oral-Lyn RapidMist. ${ }^{5}$ The commercial launch of Oral-Lynwas launched in Indian market on August 2007.5 Generex Biotechnology entered into Master Product Licensing and Distribution Agreement of OralLyn with Shreya Life Sciences, whichis the fourth largest distributor of insulin product in India. ${ }^{5}$ Generex entered into a similar agreement for the distribution of Oral-lyn in China, Hong Kong, and the following additional countries: Indonesia, South Korea, Malaysia, the Philippines in april 2008. Generex Oral-Lyn is in 
phase 3 clinical trials at several sites around the worldUS, Canada and Ukraine. ${ }^{5}$

\section{Transgene (Biotek, Andhra Pradesh) ${ }^{5}$}

Transgene has developed an oral delivery technology which combines several oral delivery approaches into a single drug delivery system. ${ }^{5}$ Applying veryunique approach, this technology involves using biodegradable novel polymeric nanoparticles loaded with insulin as a new carrier to transport the insulin across the intestinal epithelial tissues. ${ }^{5}$ Nanoparticles are solid spherical particles with a size range of 10 and $1,000 \mathrm{~nm}$ containing dispersed drugs. ${ }^{5}$ Transgene has attempted to improve the intestinal absorption of insulin and other peptides. ${ }^{5}$ The technology has been well proven in animal models, and human clinical studies are in progress. ${ }^{5}$ Drug companies are quit interested in the potential of oral insulin delivery to net a massive share of the market, and therefore, investment in research is substantial and still ongoing. ${ }^{5}$

Transgene Biotek, Biocon,and Generex Biotechnology have proven that they are insightful in the race of oral insulin delivery and definitely doing a revolutionary work in history of insulin replacement therapy. ${ }^{5}$

\section{CONCLUSION:}

The present route of insulin administration is by subcutaneous route by which insulin is presented to the body of patient in a non - physiological manner. Insulin if administered via oral route will help to eliminate the pain caused by injection, psychological barriers associated with multiple daily injections such as needle anxiety and possible infections . In addition, oral insulin is advantageous because it is delivered directly on the liver, its primary site of action, via the portal circulation, a mechanism very similar to endogenous insulin subcutaneous insulin treatment. The oral route

\section{REFERENCES:}

1. "About diabetes." World Health Organization. Retrieved 4 April 2014 .

2. "Diabetes Fact sheet $\mathrm{N}^{0} 312$ " WHO. October 2013. Retrived 25 March 2014.

3. Kitabchi, AE; Umpierrez, GE; Miles, JM; Fisher, JN (Jul2009). "Hyperglycemic crisis in adult patients with diabetes."Diabetes Care 32(7): 1335-43, doi :10.2337/dc099032. PMC 2699725. PMID 1956447

4. RSSDI textbook of diabetes mellitus. (Rev. 2nd ed.). New Delhi: Jaypee Brothers Medical Publishers. 2012. p. 235. ISBN 9789350254899

5. Kinesh V.P, Neelam D.P., Punit. B.P., Bhavesh S,B., Pragna K.S., Department of Pharmaceutics and Pharmaceutical Technology K. B Institute of Pharmaceutical Education and Reasech , Gandhinagar-India. "review article on noval approaches for oral insulin for oral delivery of insulin and current status of oral insulin products " International journal of pharmaceutical sceiences and nanotechnology. Volume3. issue3. October - December 2010

6. "National Diabetes Clearinghouse (NDIC): National Diabetes Statistics 2011". U.S. Department of Health and Human Services. Retrieved 22 April 2014.

7. Korytkowski M. When oral agents fail: practical barriers to starting insulin .Int .J. Obesity 2002, 26(3), S18-S24.

8. Lin YH. Chen CT. Liang HF, Kulkarni AR, Lee PW, Chen $\mathrm{CH}$.Novel nanoparticles for oral insulin delivery via is considered to be most acceptable and convenient route of administration for chronic therapy. Attempts have been made to achieve oral insulin delivery using various systems. It has been proven that insulin is subjected to acid catalyzed degradation in stomach, luminal degradation in intestine, and intracellular degradation. Scientists have been able to protect the insulin delivery systems from acidic environment of the stomach and target it to the intestine. Liposomes, microemulsions, nanocubicles, thiolated chitosan, chitosan microspheres and so forth have been prepared for the oral delivery of insulin. Further attempts have been made to increase the absorption enhancers such as a protinin (protease inhibitor), tween, oligoarginine, sodium glycol-cholate, deoxycholic acid, and taurodeoxycholate and membrane permeation enhancer examtheple surfactants. Overcoming limitation of these absorption enhancers and facilitators for membrane permeation is the main focus of recent research for development of satisfactory oral insulin delivery formulation.

\section{AKNOWLEDGEMENT}

First of all I thank almighty God who gave an opportunity to present this project review and my parentsMr. Ramesh Pandit and Mrs. Veena Pandit.I feel deeply obliged to Mr. TANUJ JOSHI who encouraged me to head towards and to thrive current and update knowledge. Special thank to Kinesh VP, Neelam D.P., Punit. B.P., Bhavesh S,B., Pragna K.S., Department of Pharmaceutics and Pharmaceutical Technology K. B Institute of Pharmaceutical Education and Reasech , Gandhinagar-India. who have given a valuable review article on "review article on novel approaches for oral insulin for oral delivery of insulin and current status of oral insulin products " published in International journal of pharmaceutical sciences and nanotechnology as Volume3. issue3. October - December 2010.

paracellular pathway. Nanotechnology 18: 105102, 2007, 110.

9. Gye Hwa Shin, Seoung Kyun Chung, Jun Tae Kim, Hee Joung Joung, and Hyun Jin Park, Preparation of ChitosanCoated Nanoliposomes for Improving the Mucoadhesive Property of Curcumin Using the Ethanol Injection Method, $J$. Agric. Food Chem., 2013, 61 (46), pp 11119-11126

10. Jose S, Fangueiro J.F., Smitha J , Cinu T.A, Chacko A.J. ,Premaletha K., Souto E.B. Original article "Predictive modeling of insulin release profile from cross-linked chitosan microspheres"European Journal of Medicinal Chemistry, 2013; 60:249-253.

11. Morishita M., Goto T., Nakamura K, Lowman AM, Takayama K, Peppas NA. Noval oral insulin delivery systems based on complexation polymer hydrogels : Single and multiple administration studies in type1 and type 2 diabetic rats . J. Cont. Release 2006 110:587-59.

12. Morishita M, Peppas NA. Is oral route possible for peptide delivery? Drug Discovery Today 2006 11: 19-20.

13. Agrawal V, Khan MA, Current status of oral delivery of insulin. Pharm. Tech.2001 25(10), 76-90

14. Agrawal V, Reddy IK, Khan MA. Polyethylacrylate-based microparticles of insulin for oral delivery :preparation and invitro dissolusion stability in the presencenof enzyme inhibitors. Int. J Pharm; 2001, 225(1-2),31-39.

15. Pamnani D. rality check on oral insulin.Pharma Express ,2008, 16-31. 
16. Cefalu WT. Evolving Strategies for Insulin Delivery andTherapy, Drugs, 2004,64(11),1149-116.

17. Haak T. "New Developments in the treatment of type 1 diabetes mellitus" Exp. Clin. Endocronal. Diabetes 1999, 107(3) S108-113.

18. Nakamura K, Murry RJ , Joseph JI, Peppas NA, Morishita M, Lowman AM. Oral insulin delivery system using P(MAA-gEG ) Hydrogels : Effects of network morphology on insulin delivery characteristics. J. Endocrinology2000, 164:1-6 .

19. Sajeesh S , Sharma CP. Cyclodextrine insulin complex encapsulated polymethacrylic acid based nanoparticles for oral insulin delivery.. Int. J. Pharm 2005,.294:201-216 .

20. Jain D, Panda AK, Majumdar DK.Eudragid S100 entrapped insulin microspheres for oral insulin delivery.AAPS PharmSciTech. 2005, 6(1), 1-27.

21. Lee VH.Oral route of peptides and proteins drug delivery in peptide and protein drug delivery, Chapter16, Marcel Dekker Inc., New York , 1991,691-738.

22. Tuesca A, Lowman A. The oral delivery of insulin using proteins conjugates in complexation hydrogels. Poster presentation, Biometerials and Drugs Delivery Laboratory, Dexel university, 2006.

23. Patki VP, Jagasia SH, Progress made in noninvation insulin delivery. Int .J. Pharmacol 1996, 28:143-151.

24. Chang LL,Stout LE, Wong WD. Immunohistochemical localization of insulin degrading enzyme along the rat intestinein human colon adenocarcenoma cell line(Caco-2) and in human ileum .J.Pharm.sci 1999, 86:116-119.

25. Toorisaka E, Hashida M, Ono H, Kokazu Y, Goto M. An enteric-coated dry emulsion formulation for oral insulin delivery.J.Cont.Release; 2005, 107:91-96.

26. Schilling RJ, Mitra AK. Intestinal mucosal transport of insulin. Int.J Pharm 1992,.62: 53-64.

27. Kooshapur $\mathrm{H}$, Chaideh $\mathrm{M}$. Intestinal transport of human insulin in rat. Med.J.Islamic Academy of Sciences; 1999, 12 $: 1,5-11$.

28. Cho YW, Flynn M. Oral delivery of insulin. Lancet;1989, 1518-1519.

29. Plate NA, Value IL, Sytov GA. Mucoadhesive polymers with immobilized proteinase inhibitors for oral administration of protein drugs. Biomaterials ;2002, 23(7), 1673-1677.

30. Li CL, Deng YJ. Oil-based formulation for oral delivery of insulin .J. Pharmacol 2004. 56(9),1101-1107.

31. Eaimtrakarn S, Ramaprasad YV, Ohno T, Konishi T, Yoshikawa Y, Shibata N. Absorption enhancing effects of labrasol on the intestinal absorption of insulin in rats. J.Drug Target. 2002, 10(3), 255-260.

32. Rieux A, Fievez V, Garinot M, Schneider YJ, Preat V. Nanoparticals as potentials oral delivery systems of proteins and vaccines : Amechanistic approach. J. Cont. Release; 2006, 116:1-27.

33. Gowthamarajan K, Kulkarni GT. Oral insulin- fact or fiction? Possiblities of achieving oral delivery for insulin. Resonance, 2003, 38-46.

34. Thanou M. Verhoef JC, Junginger HE. Chitosan and its derivatives as intestinal absorption enhancers. Adv. Drug Delivery .2001, 50:S91-S101.

35. Plate NA, Value IL, Sytov GA. Mucoadhesive polymers with immobilized proteinase inhibitors for oral administration of protein drugs. Biomaterials ;2002, 23(7), 1673-1677.

36. Ziv E, Lior O, Kidron $\mathrm{M}$. Absorption of protein via the intestinal walls : A quantitative models. Biochem. Pharmacol.1987, 39(7), 1035-1039.

37. Yamamoto A, Taniguchi T, Rikyuu K, Tsuji T, Fujita T, Murakami M, Mranishi S. Effects of various protease inhibitors on the intestinal absorption and degradation of insulin in rats. Pharm. Res.1994, 11(10), 1496-1500.

38. Liu H,Tang R, PanWS, Zang Y, Liu H. Potential utility of various protease inhibitors for improving the intestinal absorption of insulin in rats, J Pharm Pharmacol.2003, 55(11) :1523-1529.

39. Fujji S, YokoyamaT, Ikegaya K, Sato F, Yakko N. Promoting effects of new chymotrypsin inhibitors fk-448 on the intestinal absorption of insulin in rats and dogs. J. Drug Target.2002, 10(3),255-260.

40. Saffran M, Kumar GS, Savariar C, Burnham JC, Williams F, Neckers DC. Anew approach to oral administration of insulin and other peptides drugs. Science; 1986, 233(4768):10811084.

41. Shah RB, Ahsan F, Khan MA. Oral delivery of proteins: Progress and prognostication. Crit .Rev. Ther. Drug carrier Syst. 2002, 19(2):135-169.

42. Choudhari KB, Labhasetwar V. Liposomes as a Carrier for Oral administration of insulin: Effect of formulation factors.J. Microencapsul. 1994, 11(3), 319-325.

43. Yupeng R, SengLT. Oral GIT-Hdrogel system for treating type1 diabetes -A Report.

44. Damge C,Vrankx H,Balschmidt P, Couvreur P. Poly (alkyl cynoacrylate) Nanospheres for oral administration of insulin . J. Pharm. Sci. 1997, 86 1043-1409.

45. Al-Achi A, Greenwood R. Erythrocytes as oral delivery systems for human insulin. Drug Dev. Ind. Pharm 1998,.24 (1),67-72.

46. Chung H. Kim J, Um JY, Kwon IC, Jeong SY. SelfAssembled Nanocubicles as a Carrier for Peroral Insulin Delivery. Diabetologia 2004, 45(3), 448-451.

47. Y. Zhang Y., Wei W., Lv P,, Wang L., Ma G., Preparation and evaluation of alginate-chitosan microspheres for oral delivery of insulin, Eur. J. Pharm. Biopharm. 2011, 77 (1) 11-19.

48. Wei W., G.-H. Ma, L.- Wang Y., Wu J., Z.-G. Su, Hollow quaternized chitosan microspheres increase the therapeutic effect of orally administered insulin,Acta Biomater.2010, 6 (1) 205-209.

49. Dhawan S., . Singla A.K., Sinha V.R., Evaluation of mucoadhesive properties ofchitosan microspheres prepared by different methods, AAPS PharmSciTech 2004 5(4) .

50. Patil S.B., K.K. Sawant K.K., Chitosan microspheres as a delivery system for nasal insufflation, Colloids Surf. B Biointerfaces 2011, 84 (2) (2011) 384-389.

51. Sinha V.R., Singla A.K., Wadhawan S., Kaushik .R., Kumria R., Bansal K., Dhawan S., Chitosan microspheres as a potential carrier for drugs, Int. J. Pharm. 2004, 274 (1-2) 133 .

52. Jose S., .Fangueiro J.F., Smitha J., Cinu T.A., Chacko A.J., Premaletha K., SoutoE.B., Cross-linked chitosan microspheres for oral delivery of insulin: Taguchi design and in vivo testing, Colloids Surf. B Biointerfaces 2012, 92, 175179.

53. Martins S., Sarmento B., Souto E.B., Ferreira D.C., Insulinloaded alginate microspheres for oral delivery e effect of polysaccharide reinforcement on physicochemical properties and release profile, Carbohydr. Polym. 2007, 69 (4) 725-731.

54. Kaunisto E.,. Marucci M., Borgquist P., Axelsson A., Mechanistic modelling ofdrug release from polymer-coated and swelling and dissolving polymermatrix systems, Int. J. Pharm. 2011, 418 (1) 54-77.

55. Gao Z., Mathematical modeling of variables involved in dissolution testing, J. Pharm. Sci. 2011, 100 (11) 4934-4942.

56. Siepmann J., Peppas N.A., Higuchi equation: derivation, applications, use and misuse, Int. J. Pharm. 2011, 418 (1) 612 .

57. D.R. Paul D.R., Elaborations on the Higuchi model for drug delivery, Int. J. Pharm. 2011, 418 (1) 13-17.

58. Dokoumetzidis A., Kosmidis K., Macheras P., Monte Carlo simulations and fractional kinetics considerations for the Higuchi equation, Int. J. Pharm.2011, 418 (1) 100-103.

59. Korsmeyer R.M., Gurn R.,, Doelke E.r, P. Buri, N.A. Peppas, Mechanisms of solute release from porous hydrophilic polymers, Int. J. Pharm. 1983, 15 (1) 25-35.

60. Korsmeyer R.W., Peppas N.A.,, Macromolecular and modeling aspects of swelling-controlled systems, Control. Release Deliv. Syst. 1981,77-90.

61. Krauland AH, Guggi D, Biolaternkop-Schnurch A. Oral Insulin Delivery; The potential of the potential of thiolated chitosan insulin tablets on non diabetic rats. J Control Release 2004, 95(3), 547-55 